\author{
REVISTA DE SOCIOLOGÍA \\ $\mathrm{N}^{\mathrm{o}} 17-2003$ \\ Facultad de Ciencias Sociales - Universidad de Chile \\ (P. 31-47)
}

\title{
Dependencia Y Globalización. Nueva Perspectiva Para Una Vieja Temática.
}

\author{
Cristóbal Rovira K.* \\ Introducción?.
}

El presente texto intenta plantear cómo en Latinoamérica se puede desarrollar un nexo entre la vieja temática de la dependencia y el debate actual sobre la globalización. Para llevar a cabo esta tarea es preciso efectuar una aclaración en torno a lo que se entiende por dependencia. Pues ésta se comprende aquí no como una teoría, sino que como un concepto que junto a la noción de hibridación permite analizar la especificidad del desarrollo en América Latina. A partir de esta argumentación teórica, a continuación se aplica el definido concepto de dependencia a lo largo de la historia del continente, poniendo especial atención en la configuración del Estado-Nación durante cuatro épocas: la oligárquica, la nacionalpopular, la burocrático-autoritaria y el momento presente. Es de esta manera, como finalmente, se planteará como conclusión que la actual modernización latinoamericana es una modernización sin identidad, en tanto el carácter dependiente del continente dificulta la reconstrucción de aquel sentimiento de pertenencia que antes fue creado y protegido por el Estado.

\section{Dependencia e hibridación. Una reconstrucción teórica más allá de posturas deterministas.}

En este ensayo se fundamenta por qué hoy en América Latina seguir hablando sobre dependencia no es una simple fantasía intelectual. Precisamente en la actualidad, cuando al interior de las ciencias sociales se desarrolla una extensa discusión sobre la globalización, es posible aprender algo del viejo debate de la dependencia. Cabe recordar que lo específico de este debate era la conflictiva relación entre la esfera nacional e internacional; algo que hoy está en boga en las llamadas teorías de la globalización. En todo caso, no es posible olvidar que en los años 80 y 90 una serie de autores criticaron las teorías del desarrollo aplicadas en América Latina. Hacia esta fecha se planteó la 'crisis de las grandes teorías' y con justa razón se indicaron una serie de falacias de las teorías de la dependencia y de la modernización ${ }^{10}$. Sin embargo, a mi juicio esto no implica que ciertos elementos de

\footnotetext{
* Sociólogo, Universidad de Chile.

9 La siguiente contribución se apoya en anteriores elaboraciones, pero sobre todo en las últimas conversaciones que alcancé a tener con el Profesor Enzo Faletto. De hecho, intento aquí aplicar su pensamiento sobre la dependencia y la especificidad del desarrollo en América Latina. Aprovecho de agradecer los valiosos comentarios de Sofía Donoso, Carolina Moreno y Nicolaus von der Goltz.

${ }^{10}$ Andreas Boeckh: „Entwicklungstheorien: Eine Rückschau“. En Dieter Nohlen y Franz Nuscheler (Ed.): „Handbuch der Dritten Welt. Band 1: Grundprobleme, Theorien, Strategien”. J.H.W. Dietz, Bonn 1992.
} 
las teorías de la dependencia puedan ser utilizados para interpretar el momento actual. En este sentido, es preciso señalar que en este texto no se pretenden revivir viejos paradigmas, sino que interesa más bien confrontar la tradición de la discontinuidad de la sociología latinoamericana $^{11}$. Para poder llevar a cabo esta tarea, a lo largo del presente texto no se entiende 'dependencia' como una teoría, sino que como un concepto -de carácter típico ideal- que permite comprender e interpretar la especificidad del desarrollo latinoamericano.

En consecuencia, es posible comenzar con la siguiente afirmación: la dependencia es uno de los rasgos históricos esenciales de América Latina. La noción de lo que esta región es, fue inventada por Europa mediante los procesos de conquista y colonización, los cuales no solo establecieron un poder económico de un centro -la metrópoli-, sino que también definieron un lenguaje oficial -español y portugués- e instauraron un pensamiento religioso como válido: el catolicismo. Cuando Colón descubre tierra más allá de Occidente, los habitantes de los nuevos territorios vivenciaron una mezcla de encantamiento y dominación. Desde ese entonces el desarrollo de Latinoamérica ha estado inexorablemente imbricado con el mundo exterior. Para la región los primeros centros del mundo fueron España y Portugal, no obstante con el tiempo Alemania, Francia e Inglaterra fueron adoptando cada vez más este rol. Y a lo largo del siglo XX fueron aumentando las relaciones de dependencia con los Estados Unidos.

De tal manera, cabe señalar que a lo largo de la historia la conexión entre centro y periferia no es una sola. Dicho de otro modo, en los distintos períodos históricos se han desarrollado diferentes relaciones de dependencia. Ahora bien, en cada una de estas épocas no solo emergen conflictos y acuerdos, sino que también y sobre todo hibridaciones ${ }^{12}$. El contacto entre centro y periferia no es entonces una simple imposición foránea, puesto que constantemente sucede una asimilación. Tanto el centro como la periferia recogen mutuamente elementos a partir de sus contactos. Pero este proceso no opera de una forma simétrica, de modo que ser dependiente implica que la relación con el otro es ejercida desde una situación de inferioridad. Desde este ángulo, puede pensarse que cuando se habla de dominación el énfasis recae en quién ejerce poder sobre otro, mientras que cuando se habla de dependencia la importancia está puesta en quién es el que está siendo subordinado. Planteado así, dominación y dependencia son dos expresiones lógicamente equivalentes ${ }^{13}$.

David Booth: "Marxism and Development Sociology: Interpreting the Impasse". World Development 1985, vol. 13, no. 7. Jorge Larraín: “¿Ha muerto la teoría de la dependencia?”. Estudios Sociales, n. 60, segundo trimestre 1989. Ulrich Menzel: „Das Ende der Dritten Welt und das Scheitern der großen Theorie“. Suhrkamp, Frankfurt a.M. 1992. Holger Mürle: „Entwicklungstheorie nach dem Scheitern der großen Theorie". INEF Report1, Heft 22, 1997. Leslie Sklair: "Trascending the Impasse: Metatheory, Theory and Empirical Research in the Sociology of Development and Underdevelopment". World Development 1988, vol. 16, № 6. Peter Vandergeest y Frederick Buttel: "Marx, Weber and Development Sociology: Beyond the Impasse”. World Development 1988, vol. 16, № 6.

${ }^{11}$ En este ensayo no hay lugar para exponer este argumento en detalle. Al respecto véase Cristóbal Rovira: "Dependencia y globalización. Hacia una superación de la discontinuidad de la sociología latinoamericana". Universidad de Chile, Tesis para optar al título profesional de sociólogo, 2003.

${ }^{12}$ Néstor García Canclini: "Culturas híbridas. Estrategias para entrar y salir de la modernidad". Editorial Paidós, Argentina 2001 (primera edición reactualizada).

${ }^{13}$ Guillermo O’Donnell y Delfina Linck: "Dependencia y autonomía". Amorrortu Editores, Buenos Aires 1973, p. 17. 
El concepto de la hibridación tiene un valor heurístico particular, ya que gracias a él queda en evidencia por qué por lo menos en la actualidad es dudoso para la teoría sociológica el supuesto carácter colonialista y/o imperialista de la relación entre centro y periferia. Los países latinoamericanos son hoy el resultado de un entrelazamiento de tradiciones precolombinas, pensamiento hispano católico y política racional laica. Esta mezcla se ha ido constituyendo en una constante tensión, puesto que en cada país de la región han estado los elementos que soportan este entrelazamiento en grados diferenciales ${ }^{14}$. Pero esta tensión se debe también a la forma que adoptan los procesos de hibridación, puesto que allí se definen mecanismos de inclusión y exclusión. De esta manera, resulta posible investigar los procesos de hibridación en relación a las asimetrías culturales y de poder y prestigio. Es así como resulta evidente que la dependencia no es una mera imposición unilateral. En la periferia existen actores sociales que operan como reguladores, esto es, como sujetos que manejan el contacto con el exterior, lo interpretan y luego lo institucionalizan a la realidad propia. Ellos son quienes más contacto mantienen con la esfera internacional y por esto es que usualmente hacen las veces de mediadores o traductores para el mundo nacional. Y en el desarrollo histórico de América Latina, ha sido el Estado un actor privilegiado tanto para manejar los vínculos de dependencia, como para dirigir los procesos de hibridación. En consecuencia, se verá a lo largo de este ensayo cómo opera esta compleja relación entre centro y periferia a partir del desarrollo histórico que adopta la relación entre Estado y Sociedad en Latinoamérica.

\section{La creación del Estado latinoamericano: una independencia ambigua.}

Es una tesis conocida y poco debatida que en los países latinoamericanos la nación fue construida prácticamente de forma única por el Estado ${ }^{15}$. Antes de la emancipación de España y Portugal no existían naciones que hayan reivindicado su autonomía. Las elites criollas no tenían acceso al poder y este factor fue de inmensa importancia para la emergencia de los procesos de emancipación política. Estas elites habían desarrollado importantes progresos en sus territorios locales, pero tenían muy pocas posibilidades de ascenso social, en tanto los señores coloniales mantenían un férreo monopolio del poder. Por tanto, era solo una cuestión de tiempo para que irrumpieran las tendencias emancipatorias. En este sentido, es preciso indicar que los movimientos libertarios de América Latina no son directamente comparables con los casos de Europa y de Norteamérica $^{16}$.

\footnotetext{
${ }^{14}$ En gran medida de aquí deriva la diversidad al interior de la región latinoamericana que usualmente se pasa por alto. Al respecto basta señalar el siguiente dato: mientras países como Argentina, Chile y Uruguay presentan tasas de población indígena menores al $10 \%$ de la población total, países como Bolivia, Ecuador, Guatemala y Perú tienen niveles de población indígena cercanas o mayores al $40 \%$ de la población total. Alexia Peyser y Juan Chackiel: "La población indígena en los censos de América Latina". En CELADE/CIDOB/FNUAP/ICI: "Estudios sociodemográficos de pueblos indígenas". Santiago de Chile 1994, p. 34.

${ }^{15}$ Tulio Halperin Donghi: "Historia contemporánea de América Latina". Editorial Alianza, España 2001. Benedict Anderson: "Die Erfindung der Nation. Zur Karriere eines erfolgenreichen Konzepts". Frankfurt a.M./New York, Campus 1996.

${ }^{16}$ En todo caso, cabe señalar contra el sentido común que los procesos de emancipación europeos y norteamericanos no solo se caracterizaron por un aumento de las libertades, sino que también por la introducción de mecanismos de disciplinamiento. Peter Wagner: "A sociology of modernity: liberty and
} 
En la región latinoamericana, la revolución política contra el dominio de la conquista fue una revolución oligárquica. Las elites criollas fundaron un aparato administrativo en los terrenos existentes bajo el respeto del principio uti possidetis. Para ello, las ideas emancipatorias propias de la modernidad fueron sus armas intelectuales. Es así como se instaura quizás la mayor -y aún viva- paradoja de América Latina: por una parte, se importa el discurso de la fraternidad, libertad e igualdad, pero por otra, esta constelación de ideas es escasamente institucionalizada en los órdenes sociales y raramente internalizada por los actores sociales ${ }^{17}$. Se trata entonces de un proceso de hibridación-interpretación de valores de otra cultura- que se constituye como un mecanismo a través del cual algunos círculos sociales logran instaurar una posición hegemónica. Por esto que José Medina Echavarría señalara la existencia de una constelación originaria de América Latina, la cual imprime un carácter sui generis a cualquier intento de desarrollo ${ }^{18}$. A contar del período de independencia, en estas tierras los procesos históricos se caracterizan por una compleja combinación entre importación de ideas foráneas y aplicación de medidas autóctonas. Dependencia e hibridación son así elementos claves para comprender la historia de la región.

Desde este ángulo, el hecho de que las elites criollas no hayan vigorizado un pensamiento intelectual autónomo, en tanto privilegiaron la introducción de ideas foráneas, no puede ser analizado como una simple imposición cultural. Gracias a este mecanismo, las elites lograron dirigir los procesos de independencia en su beneficio propio. En este sentido, la reproducción de una dependencia entre centro y periferia obedecía al interés interno de generar procesos de hibridación que delimitasen quien pertenece a la sociedad. Es así como comienzan a establecerse y reproducirse mecanismos de inclusión y exclusión social. "La dependencia no era simple explotación y coacción, existía comunidad de intereses entre grupos dominantes locales y externos; la dependencia no enfrentaba así al 'conjunto' de los intereses de una sociedad con otra. La interdependencia era un hecho y eso vinculaba sociedades desarrolladas con subdesarrolladas, pero también permitía establecer correspondencia de intereses entre los grupos dominantes de ambas sociedades" $"$.

La emergencia de los Estados nacionales en el continente latinoamericano debe ser comprendida como la construcción de órdenes legítimos que posibilitaron a las elites criollas el ejercicio del monopolio del poder interno. Esta transformación del orden político tuvo diferentes niveles de éxito en los países de la región, lo cual dependió fundamentalmente de tres factores. Primero: el grado interno de diferenciación social y el conflicto en torno al establecimiento de una dominación nacional legítima. ¿Cuántos grupos disputan el control del poder político que se está constituyendo y de qué manera logran

discipline". Routledge, London 1994. Alain Touraine: "Crítica a la modernidad". Fondo de Cultura Económica, México 1995.

17 José Medina Echavarría: "Consideraciones sociológicas sobre el desarrollo económico en América Latina". Editorial Solar/Hachette, Buenos Aires 1964, p. 64. Enzo Faletto y Julieta Kirkwood : "El liberalismo romántico". Editorial El Cid, Caracas 1977, p. 25.

${ }^{18}$ Adolfo Gurrieri: "José Medina Echavarría. Un perfil intelectual". Revista de la CEPAL No 9, Diciembre de 1979, p. 156.

${ }^{19}$ Enzo Faletto: "La CEPAL y la sociología del desarrollo". Revista de la CEPAL No 58, abril de 1996, p. 196. 
ellos conciliar esta disputa? ${ }^{20}$ Segundo: el nivel del control nacional de la producción económica y el grado de penetración de los capitales extranjeros. ¿Pueden los nuevos regímenes mantener el heredado sistema de exportación de la colonia o es éste controlado por un poder foráneo, estableciéndose así un sistema de enclave? ${ }^{21}$ Tercero: la efectividad de la oligarquía al momento de instaurar sistemas simbólicos nacionales que permitan su manejo en provecho propio. ¿Puede la oligarquía mantener restringidos los niveles de alfabetización -es decir, limitar la expansión de la opinión pública- y establecer una definición entre alta cultura y cultura popular? ${ }^{22}$

Más allá del éxito que alcanza esta transformación del orden político, a lo largo de todo el continente se establece un modelo de desarrollo que permite una modernización y conlleva la fundación de Estados oligárquicos. Este último adjetivo revela que los territorios nacionales fueron controlados por una pequeña elite, la cual utilizaba el progreso económico en su propio beneficio, monopolizaba el acceso al poder estatal y controlaba las posibilidades de ascenso social ${ }^{23}$. Las sociedades latinoamericanas de aquella época se caracterizaban por la estructura de la hacienda y, por lo tanto, la población urbana no alcanzaba a ser más de un quinto de la población total. Además faltaba mucho para que se estableciera una política educacional masiva, lo que permitiría la instauración y vigorización de una opinión pública propiamente tal.

Pero la emergencia del Estado latinoamericano no tuvo solo consecuencias internas sino que también externas. Ante este nuevo escenario disminuyeron las relaciones de dependencia con España y Portugal, mientras que nuevas fuerzas internacionales entraron en juego. Esto no es válido tan solo para las relaciones económicas, sino que también para los intercambios culturales. El instinto de imitación se movió desde Lisboa y Madrid hacia Berlín, Londres y París. Un ejemplo radical en este sentido se encuentra en la vida y obra del intelectual -y también presidente de Argentina-, Domingo Faustino Sarmiento (18111888): para él era la inmigración anglosajona el camino más rápido y mejor para el desarrollo de su país, puesto que así se introduce una mentalidad adelantada ${ }^{24}$. El acento no está aquí en la interpretación de una cultura distinta y su traducción a la realidad propia. El ideal de aquella época era más bien el de la simple imitación y por esto es que rara vez emergieron iniciativas autónomas. ¿Por qué debían promover las elites nuevas actividades económicas si el control de la anterior producción colonial -prácticamente solo exportación de materias primas para el centro- aportaba suficientes ganancias para su círculo social? Que con el tiempo capitales alemanes, franceses e ingleses vayan desplegando los nuevos sectores de la economía -como por ejemplo mediante la organización del sistema de trenes- era solo una demostración de cómo los hijos del movimiento de la emancipación no eran fieles representantes del espíritu capitalista moderno.

\footnotetext{
${ }^{20}$ Edelberto Torres Rivas: "La nación: problemas teóricos e históricos". En Norbert Lechner (Editor): "Estado y política en América Latina". Editorial Siglo XXI, México 1981, p. 113 -114.

${ }^{21}$ Fernando Henrique Cardoso y Enzo Faletto: "Dependencia y desarrollo en América Latina". Editorial Siglo XXI, México 1969, p. 40-41.

${ }^{22}$ Néstor García Canclini, op. cit. 2001, p. 83.

${ }^{23}$ Jorge Graciarena: "El Estado latinoamericano en perspectiva: figuras, crisis, prospectivas". Pensamiento Iberoamericano, Revista de Economía Política, №5 1984, p. 50.

${ }^{24}$ Nikolaus Werz: "Pensamiento sociopolitico moderno en América Latina". Editorial Nueva Sociedad, Caracas 1995, p. 45-47.
} 
En este lugar, cabe indicar una vez más que la dependencia no es simple y necesariamente una imposición del centro, sino que ésta es el resultado de estrategias y estructuraciones internas -lo cual parafraseando a Weber puede ser bien un omitir o permitir. Cuando en América Latina se funda el Estado nacional se modifican radicalmente las relaciones de dependencia con el centro. Con mayor o menor efectividad -Sudamérica/México y el Caribe respectivamente- emergen órdenes políticos autónomos, los cuales tan solo en un lugar secundario tenían como objetivo una real independencia cultural y económica. La reproducción de las relaciones de dependencia tanto con la antigua metrópoli como con el nuevo centro resultaba funcional para las elites. Así como los antiguos señores coloniales no tenían interés en romper las relaciones de dependencia e incluir a los sectores criollos de las sociedades latinoamericanas, los florecientes grupos políticos que llevaron a cabo la emancipación frente a la colonia tampoco tenían la motivación de romper los vínculos de dependencia, sino que su interés residía en monopolizarlos y dirigirlos en beneficio propio. Pues de esta manera podían ellos manejar procesos de hibridación que aseguraban las asimetrías de poder internas, situación que fue sostenible hasta principios del siglo XX.

\section{El Estado nacional-popular: la constitución del principio de la ciudadanía.}

Las oligarquías del siglo XIX actuaron mediante el Estado para lograr la creación de una nación. Pero esta última se constituyó solo en parte gracias a lo que comenzaba a definirse como tradiciones y símbolos nacionales. La política de desarrollo hacia afuera de las elites posibilitó el lento surgimiento de nuevos grupos y clases sociales, las cuales gradualmente fueron ejerciendo presión para su integración social. La idea de la nación comenzó a ser cada vez más una materia en discusión, sobre todo producto de la creciente migración del campo a la ciudad. Dejó de ser evidente quién efectivamente pertenecía a la sociedad, de modo que la forma como se había venido construyendo la identidad nacional ya no era creíble para el conjunto de sujetos que vivían en una misma comunidad política. A regañadientes las elites tuvieron que establecer compromisos con los nuevos grupos sociales. El resultado de esto fue una nueva organización del Estado, la cual permitió una refundación de la idea de la nación mediante una gradual política de integración social. En otras palabras, con el advenimiento de la crisis del Estado oligárquico fue cada vez mayor la presión por el establecimiento de derechos ciudadanos. Y fue justamente el Estado nacional-popular y/o desarrollista quien tuvo un rol preponderante en esta tarea. Esto implica que en América Latina una nación de ciudadanos fue constituida en relación con y no en oposición al Estado ${ }^{25}$. En los países latinoamericanos se pudo desarrollar el principio de la identidad nacional en la medida que los grupos excluidos de la sociedad comienzan a tener acceso al poder estatal. Es por esto que puede señalarse que lo propio del Estado nacional-popular y/o desarrollista fue su capacidad para instaurar los derechos ciudadanos en el continente.

En resumen, puede pensarse que la oligarquía fue vigorizando sus vínculos de dependencia con Europa, pero simultáneamente fue perdiendo su capacidad para manejar dichos vínculos y dirigir los procesos de hibridación de una forma determinada. Esto permitió un importante giro, ya que gradualmente se fue incorporando el modelo de desarrollo europeo

\footnotetext{
${ }^{25}$ Enzo Faletto: “La función del Estado en América Latina”. Revista Foro, Colombia №23 1994, p. 13.
} 
a la realidad latinoamericana y así es como se implanta el principio de la ciudadanía. De hecho, se intenta imitar el funcionamiento de los Estados de Bienestar europeos y por esto el rápido auge que tuvo la política económica keynesiana propiciada por la CEPAL. Sin embargo, dadas las condiciones particulares de América Latina, el resultado fue un producto híbrido. Mientras en la historia europea, y principalmente anglosajona, la obtención de los derechos ciudadanos fue fundamentalmente una reivindicación de las garantías de las personas frente a la autoridad, en el caso de Latinoamérica los derechos de ciudadanía se obtuvieron más bien como una obligación del Estado de garantizar la satisfacción de ciertas demandas básicas vinculadas a la existencia social.

Ahora bien, dado el carácter sui generis del Estado nacional-popular que se instaura con posterioridad de la crisis oligárquica, la sociedad civil se ve atrofiada por la excesiva fuerza que adquiere la administración pública en general y el poder político en particular. Una de las consecuencias de esto, es que la racionalidad comunicativa de la sociedad civil operaba principalmente cuando esta entidad aspiraba a la movilización política. Es de esta manera como se posibilita una suerte de colonización de la subjetividad por parte de la racionalidad política $^{26}$. Uno de las expresiones de esta problemática es el ciclo de vida del muralismo mexicano, el cual fue fundado por artistas como Rivera (1886-1957) y Siqueiros (18961974). Los exponentes del muralismo se definían como una vanguardia cultural propia de la modernidad que aspiraba a la emancipación del hombre. Por esto es que dichos artistas tenían como objetivo la construcción de gigantescos cuadros públicos -democratización-, en los cuales debía representarse la 'verdadera' realidad del país -construcción de la identidad nacional. Uno de los elementos centrales de estas obras era la revelación de la explotación de los indígenas y de las clases desposeídas, primero por los españoles y luego por las oligarquías. Pero esta vanguardia pudo desarrollarse fundamentalmente gracias a la relación que los artistas de este movimiento mantenían con la política oficial del Estado ${ }^{27}$. Por tanto, tal como señala García Canclini, "la historia de la cultura mexicana de los años treinta y cincuenta muestra la fragilidad de esta utopía y el desgaste que fue sufriendo a causa de condiciones intraartísticas y sociopolíticas. El campo plástico, hegemonizado por el realismo dogmático, el contenidismo y la subordinación del arte a la política, pierde su vitalidad previa y consiente pocas innovaciones" ${ }^{\text {28 }}$.

Más allá de esta problemática, cabe señalar que entre los años 30 y fines de los 60 la identidad nacional de los países latinoamericanos efectivamente se fue modificando. Grupos sociales que antes estaban excluidos de la sociedad pudieron gradualmente ir obteniendo sus derechos ciudadanos y así es como la idea de la nación se fue transformando. No es casualidad entonces que en esta época prácticamente todos los movimientos sociales recurrieran a un calificativo determinado: nacional popular. Mientras la palabra 'nacional' hacía referencia a la creciente influencia que el Estado tenía en su territorio, el concepto 'popular' se utilizaba para dar cuenta de la progresiva inclusión de nuevos miembros a la comunidad política. Ambas nociones debían ir juntas, puesto que el

\footnotetext{
${ }^{26}$ Manuel Antonio Garretón: "La transformación de la acción colectiva en América Latina". Revista de la CEPAL No 76, Abril del 2002, p. 10.

${ }^{27}$ De hecho, la primera obra del muralismo mexicano surgió en 1921 a partir del encargo hecho por el gobierno de México a Diego Rivera. Gustavo y Hélène Beyhaut: "América Latina. De la independencia a la segunda guerra mundial”. Editorial Siglo XXI, México 1985, p. 251.

${ }^{28}$ Néstor García Canclini, op. cit. 2001, p. 93.
} 
Estado debía actuar a favor del pueblo, otorgando éste último a cambio legitimidad al orden social. De tal manera, los actores de la cultura, de la política y de la economía observaban como gracias al obrar del Estado aumentaban sus respectivos espacios de acción, en tanto se abrían oportunidades para que participaran cada vez más individuos. Esta configuración histórica recibe desde la teoría sociológica el nombre sociedad estado-céntrica ${ }^{29}$. Tal como indica el nombre, el Estado era el actor social primordial y por tanto la autonomía de la sociedad propiamente tal era bastante restringida. Quienes en mayor grado se beneficiaban del crecimiento del aparato estatal eran las clases medias, ya que ellas tendieron a monopolizar los mecanismos de integración social.

Sin embargo, con el pasar del tiempo la sociedad estado-céntrica latinoamericana comenzó a tener problemas para mantener el desarrollo nacional. Sin duda alguna crecieron los derechos y mercados nacionales, pero no todos los ciudadanos accedían a éstos. Por tanto, la presión política por el aumento de la incorporación de los excluidos se fue haciendo cada vez mayor. La aparición de regímenes populistas - paradigmático es el caso de Perón en Argentina- fue uno de los primeros síntomas respecto a la situación crítica de la época. Estos regímenes tenían una masiva base que se sustentaba en el personalismo político y en la proposición de soluciones simplistas, las cuales trascendían una ética política de la responsabilidad. En la práctica, dichos regímenes populistas eran una señal de decadencia de la sociedad estado-céntrica latinoamericana. La primera y fácil etapa de sustitución de importaciones ya se había llevado a cabo, pero a continuación faltaban elementos para proseguir con la política de desarrollo económico propiciada por la CEPAL. Esto implica que comenzó a flaquear la base económica que permitía la tarea de distribución ejercida por el Estado. Producción ineficiente, falta de tecnología, creciente inflación y aumento del endeudamiento eran algunos de los signos que demostraban la crítica situación de los países latinoamericanos hacia fines de los años 60 .

\section{El Estado burocrático-autoritario: una manifestación de la especificidad del desarrollo latinoamericano.}

El modelo de desarrollo propio del Estado nacional-popular fue llegando a una encrucijada. Estaba, por una parte, el estancamiento de la economía y, por otra, la creciente movilización social. Las directrices partidarias se fueron guiando más por una ética de la convicción que de la responsabilidad, la tensión política fue aumentando $\mathrm{y}$, en consecuencia, las posibles soluciones se hicieron cada vez más irreconciliables. Al mismo tiempo, desde el centro comenzó una búsqueda de oportunidades de inversión, ya que los noveles mercados internos latinoamericanos se fueron haciendo interesantes tanto para la producción como para la comercialización de mercancías. Estos procesos fueron financiados en gran medida por los llamados petrodólares. Ante este escenario, la crisis de la deuda externa y la internacionalización de los mercados era tan solo una cuestión de tiempo. Ahora bien, la forma interna de esta reestructuración se reflejó en la configuración de un Estado burocrático-autoritario, una tesis que teóricos de la dependencia como Cardoso y Faletto postulaban cuando tan solo un golpe militar había acontecido en el continente (1964 en Brasil). Este nuevo tipo de régimen autoritario resulta de la necesidad

\footnotetext{
${ }^{29}$ Manuel Antonio Garretón: "La sociedad en vivi(re)mos". Editorial LOM, Santiago de Chile 2000. Norbert Lechner: "Tres formas de coordinación social". Revista de la CEPAL, abril 1997, p. 10.
} 
de una profundización en la modernización, la cual requiere de un marco de represión estable para poder incentivar la llegada de capitales internos y sobre todo externos ${ }^{30}$.

Resulta importante señalar que en el libro de Guillermo O'Donnell, donde se presenta la tesis sobre la formación de los estados burocrático-autoritarios, se examina el nexo con el concepto de la dependencia ${ }^{31}$. El autor mencionado indica que el derrumbe generalizado de la democracia en América Latina es un indicador de la especificidad del desarrollo histórico que adopta esta región. Las teorías clásicas de la modernización postulaban que mientras más desarrollado un país, más democrático sería éste. Pero O’Donnell plantea que en el caso de Latinoamérica no sucede esto. De hecho, en países como Argentina y Brasil, que hacia los años 60 ya habían alcanzado un nivel de desarrollo importante, emergen regímenes burocrático-autoritarios que desean continuar con el proceso de modernización económica, pero no están interesados en proseguir con el proceso de democratización social. Esta situación se terminará haciendo generalizada en América Latina, en tanto las fuerzas armadas asumen el rol de mantener el sistema de dominación interno, modificando las relaciones que se mantienen con el exterior en un aspecto crucial: la apertura de los mercados internos. Se entra así gradualmente en una nueva fase de modernización, la cual exige una rearticulación del poder interno. Se implementa una estrategia de crecimiento por exportación, apoyada en una asociación entre capital transnacional y capital nacional. Dado que la fuerte disparidad de ingresos, la caída de los salarios reales y una alta desocupación estructural son elementos intrínsecos a la implementación del nuevo modelo económico, se acentúa la función represiva del aparato estatal. Pero lo principal del orden autoritario es que "[...] imputa el fracaso de la democracia a un exceso de participación que impediría gobernar. Fracasado el objetivo desarrollista de incrementar la capacidad administrativa del aparato gubernamental, se propone, por el contrario, descargar a un estado sobregirado en sus responsabilidades y entregar la satisfacción de las necesidades sociales a la lógica del mercado",32.

En definitiva, dado el carácter dependiente de América Latina, la encrucijada histórica de fines de los años 60 y comienzos de los 70 es resuelta de una forma singular: el llamado autoritarismo burocrático. Ante el reordenamiento de la economía internacional y la crisis del modelo de desarrollo nacional, la modernización es continuada a costa de la democratización social. En otras palabras, dadas las condiciones históricas de ese entonces, existe -en términos sociológicos- una afinidad electiva entre internacionalización del mercado interno y la adopción de un carácter burocrático-autoritario por parte del Estado. Esto revela una vez más la especificidad del desarrollo latinoamericano. Los grupos sociales que asumen la dirección de los países del continente en este momento de crisis dan forma a un producto absolutamente híbrido: un Estado autoritario modernizante que se apoya en el neoliberalismo y la doctrina de seguridad nacional. Sucede así una importación de ideas foráneas -neoliberalismo- que es esgrimida por ciertos grupos sociales -anillos técnico burocráticos asociados al aparato militar- para consolidar su posición hegemónica interna. A su vez, los defensores del nuevo modelo de desarrollo tienden a asociarse con los

\footnotetext{
${ }^{30}$ Dieter Nohlen y Rainer-Olaf Schulze: "Lexikon der Politikwissenschaft. Band 1". Verlag C.H. Beck, München 2002, p. 95.

${ }^{31}$ Guillermo O’Donnell: “Modernización y autoritarismo”. Editorial Paidós, Buenos Aires 1972.

${ }^{32}$ Norbert Lechner: “Epílogo”. En Norbert Lechner, op. cit. 1981, p. 310.
} 
poderes económicos externos, para monopolizar los vínculos de dependencia. Las reglas del libre mercado comenzarán a ser consentidas y puestas en marcha por el Estado. Es así como el anterior Estado nacional-popular se fue transformando en uno neoliberal. Por cierto que este proceso se fue dando en los distintos países latinoamericanos de forma particular, pero en todos los casos existe un elemento en común: "el Estado pasó a ser el elemento estratégico que funciona como una esclusa para permitir que se abran las puertas por las cuales pasa la historia del capitalismo en las economías periféricas que continúan modernizándose, ${ }^{, 33}$.

Ahora bien, en este nuevo escenario el nexo entre Estado y Sociedad se hará cada vez más problemático, ya que dicho nexo comenzará a dejar de estar definido por la nación y emergerá a cambio la idea del mercado como sistema de autorregulación social. Producto de esta transformación, las sociedades de la región se verán afectadas en dos aspectos medulares. Por una parte, al efectuar el Estado una política que fomenta la diferenciación funcional, se concentra éste en las tareas de coordinación y deja de lado sus antiguas tareas de integración social. Además el Estado se ve exigido por una serie de nuevas tareas que muchas veces sobrepasan su capacidad. Por otra parte, los agentes económicos nacionales y transnacionales ganan un inmenso poder, lo que muchas veces les permite actuar como enclaves autoritarios: en vez de los regímenes políticos, son ellos quienes toman decisiones trascendentales y lo hacen fuera de las reglas democráticas ${ }^{34}$. En consecuencia, gran parte de la población latinoamericana se terminará haciendo la siguiente pregunta: ¿actúa el Estado a favor de la nación o a favor de determinados grupos sociales? Desde este ángulo, puede plantearse que en los países dependientes, cuando se impone la lógica del mercado internacional, la tendencia es hacia el debilitamiento de la relación entre el Estado y la nación ${ }^{35}$.

\section{La Globalización En América Latina: Adiós Ciudadanos, Bienvenidos Consumidores.}

En América Latina quizás el primer tema que va de la mano con la palabra globalización sea la configuración de una nueva economía mundial y el establecimiento del libre mercado. Una de las transformaciones más radicales que han sufrido los países de esta región es la aplicación del llamado 'Consenso de Washington', una política económica que se caracteriza por tres elementos: la desregulación del mercado del trabajo, la privatización de las empresas públicas y, por último, la liberalización de los mercados de comercio y finanzas $^{36}$. A partir de la aplicación de esta fórmula los países latinoamericanos efectivamente se han globalizado económicamente, aunque el costo social de este proceso ha sido alto. La rapidez e intensidad de los cambios económicos ha socavado las tradicionales formas de asociatividad, de confianza social y de reciprocidad, de manera que no es una casualidad que desde los años 90 en adelante el tema del capital social haya

\footnotetext{
${ }^{33}$ Fernando Henrique Cardoso y Enzo Faletto: “Post Scriptum”. Capítulo adicional para las ediciones del libro Dependencia y Desarrollo en América Latina en inglés y alemán y las nuevas reediciones en castellano. Desarrollo Económico, vol. 17, n. 66, julio-septiembre 1977, p. 289.

${ }^{34}$ Manuel Antonio Garretón, op. cit. 2000, p. 126-127.

${ }^{35}$ Enzo Faletto: "La especificidad del Estado latinoamericano". Revista de la CEPAL No 38, Agosto de 1989 , p. 71.

${ }^{36}$ Emilio Klein y Víctor Tokman: "La estratificación social bajo tensión en la era de la globalización". Revista de la CEPAL No 72,2000, p. 8.
} 
ganado preponderancia en la sociología latinoamericana ${ }^{37}$. Dicho de otro modo, hoy en día toda la región enfrenta una problemática en común: cómo lograr una mayor integración económica sin que por medio de ésta aumente la desintegración social.

Pero en la sociología latinoamericana, el discurso de la globalización no solo se asocia con las reestructuraciones económicas de las últimas dos décadas, sino que también -y sobre todo en el último tiempo- con las transformaciones culturales que los países de la región han vivido y están viviendo. Los teóricos de la región cada vez toman mayor conciencia que los procesos globalizadores -y las imágenes que los representan- se vienen constituyendo por una creciente circulación de capitales, bienes y mensajes, pero también de personas que se trasladan entre países y culturas como migrantes, turistas, estudiantes o profesionales $^{38}$. Justamente debido a esto se puede plantear que la imagen tradicional de la sociedad se ha puesto en entredicho, ya que los códigos mediante los cuales históricamente se observa la realidad social han ido perdiendo gradualmente su validez. La pregunta por la identidad colectiva se torna particularmente vigente, en tanto lo nacional ha dejado de ser obvio y al mismo tiempo no emergen referentes comunes que definan un sentido compartido a la vida en sociedad. Esto afecta particularmente a América Latina, ya que como se señaló con anterioridad, el carácter dependiente de los países de la región imprime un sello particular a sus procesos históricos. Sucede que en América Latina, la reforma neoliberal del Estado rompe las tradicionales alianzas entre Estado y Sociedad, de modo que se produce gradualmente un vaciamiento sobre el discurso de la identidad nacional. Por esto es que hoy en día se plantea que el imaginario colectivo de una sociedad estadocéntrica está irresolublemente puesto en entredicho ${ }^{39}$.

En todo caso, este diagnóstico no debe ser comprendido como un simple lamento sobre el decaimiento de un 'maravilloso' Estado, puesto que hoy en día es evidente, que éste puede ser no solo ineficiente o corrupto, sino que también represor. El problema está en la redefinición de la comunidad política. Dado que en Latinoamérica tanto el principio de la ciudadanía como el de la nación fue constituido principalmente por el Estado y solo de forma secundaria por la sociedad civil, politólogos y sociólogos se preguntan cómo es posible construir hoy una identidad capaz de fundar un 'sentimiento de nosotros' entre los ciudadanos. De no cumplirse esta tarea, es cuestionable si acaso la democracia efectivamente se podrá arraigar en los países latinoamericanos. Toda forma democrática de gobierno supone una comunidad de personas - la nación- que en cierta medida representa una unidad política autónoma que aspira a su autodeterminación colectiva. En consecuencia, el problema no es tanto el declive de una identidad nacional, sino que la ausencia de un nuevo imaginario colectivo que sea capaz de otorgar un sentido de pertinencia a la comunidad política.

Si en los países de América Latina efectivamente parece haber un vaciamiento de la identidad nacional, no deja de ser menor el rol que juega en esto la creciente interconexión

\footnotetext{
${ }^{37}$ Raúl Atria y Marcelo Siles (Compiladores): "Capital social y reducción de la pobreza en América Latina y el Caribe: en búsqueda de un nuevo paradigma”. CEPAL, Santiago de Chile 2003.

${ }^{38}$ Néstor García Canclini: “La globalización imaginada”. Editorial Paidós, Buenos Aires 2000, p. 63.

${ }^{39}$ Manuel Antonio Garretón, op. cit. 2002, p. 13-14. Norbert Lechner, op. cit. 1997, p. 8. Manuel Castells: “Globalización, identidad y estado”. Santiago de Chile, PNUD 1999, p. 12
} 
mundial y la rearticulación de las relaciones de la dependencia. Hoy más que nunca los procesos de hibridación toman una velocidad inusitada, justo cuando el sujeto que históricamente en los países latinoamericanos ha funcionado como mediador entre lo nacional y lo internacional -el Estado- se encuentra en franco deterioro. Por cierto que en todos los territorios del mundo ya no es fácil distinguir qué es lo propio y lo ajeno, pero para los países periféricos resulta particularmente dificultoso reconstruir un proyecto país. El carácter dependiente de la región latinoamericana hace que los procesos de globalización se ejerzan desde una situación de inferioridad. En la medida que el Estado pierde la capacidad para generar un sentido de pertenencia es el mercado el que pasa a suplir esta necesidad antropológica mediante el consumo. Gracias a él los sujetos tienen la posibilidad de definir hábitos, sentimientos compartidos y modos de relación y de comunicación social. Pero en países como los nuestros, donde los niveles de desigualdad social son muy altos, el consumo sirve también para aumentar la brecha objetiva y subjetiva entre quienes están integrados y excluidos de la sociedad. "Pasamos de situarnos en el mundo como un conjunto de naciones con gobiernos inestables, frecuentes golpes militares, pero con entidad sociopolítica a ser un mercado: un repertorio de materias primas con precios en decadencia, historias comercializables si se convierten en músicas folclóricas y telenovelas, y un enorme paquete de clientes para las manufacturas y las tecnologías del norte, pero con baja capacidad de compra, que paga deudas vendiendo su petróleo, sus bancos y sus aerolíneas. Al deshacernos del patrimonio y de los recursos para administrarlo, expandirlo y comunicarlo, nuestra autonomía nacional y regional se atrofia" ${ }^{, 40}$.

Ahora bien, que el mercado sea considerado por muchos como un mecanismo de autorregulación social y que el consumo opere cada vez más como un dispositivo de integración y exclusión social, se explica en gran medida porque en los últimos veinticinco años las relaciones de dependencia de América Latina con Estados Unidos han aumentado notablemente. Se ha redefinido el modelo de sociedad al cual se aspira. "Las modificaciones ocurridas mientras se transitaba de la subordinación europea a la norteamericana en los mercados agricolas, industriales y financieros, en la producción, circulación y consumo de tecnología y culturas, y en los movimientos poblacionales turistas, migrantes y exiliados- alteraron estructuralmente el carácter de nuestra dependencia" 41 . De tal manera, no parece descabellado pensar que mientras el Estado nacional-popular imitaba fundamentalmente el modelo de desarrollo europeo y, por tanto, realizaba los procesos de hibridación principalmente en función de los vínculos de dependencia que se mantenían con dicho continente, lo que se potenciaba era la constitución de ciudadanos. En cambio, cuando la región latinoamericana comienza a depender cada vez más de los Estados Unidos, los procesos de hibridación asimilan fundamentalmente los componentes de esta cultura y de ahí que hoy en día se observe en América Latina una creciente vigorización de los consumidores. Por esto que en la actualidad, una de las preguntas de fondo que ronda en la sociología latinoamericana es la siguiente: ¿cuál sistema tendrá en la región más fuerza para la redefinición de una identidad

\footnotetext{
${ }^{40}$ Néstor García Canclini: “Latinoamericanos buscando lugar en este siglo”. Editorial Paidós, Buenos Aires 2002 , p. 46.

41 Néstor García Canclini: “Consumidores y ciudadanos. Conflictos multiculturales de la globalización”. Editorial Grijalbo, México 1995, p. 14.
} 
colectiva: la política o la economía? Dicho de otro modo: ¿quiénes se sienten miembros de la sociedad lo harán en tanto ciudadanos o consumidores?

\section{Modernización sin identidad: el discurso sociológico latinoamericano sobre la globalización.}

En el escenario actual, si un país latinoamericano no realiza una adaptación a los circuitos globales, parece que no tiene posibilidad alguna de superar su condición periférica. Por esto es que en dichos países los procesos de globalización sean asumidos como una cuestión de vida o muerte. O se actúa a nivel global o de lo contrario simplemente se evaporan las posibilidades de desarrollo. Pero junto a esta necesidad de adaptación a los nuevos tiempos, una temática se hace cada vez más profunda: mientras más abre sus fronteras un país dependiente para lograr la ansiada modernización, más cuestionable se hace su identidad propia. Cuando los capitales transnacionales compran las firmas locales, las organizaciones internacionales tienen más poder que los gobiernos nacionales en ciertos ámbitos y la producción multimedia global fagocita la producción cultural autóctona, se torna virulenta la pregunta por la particularidad de la nación. En consecuencia, pareciera ser que para los países de la región el tema de la globalización origina una confrontación con la posición que se detenta en el mundo; una confrontación que se deja resumir en una doble pregunta: ¿cómo es posible realizar una modernización económica y socialmente adecuada y cuál es la identidad propia?

Cabe señalar que esta problemática sucede tanto en Europa y Estados Unidos como en América Latina. Pero este último continente no solo se está quedando sin proyectos nacionales, sino que la posible construcción de un orden supranacional que no sea una simple integración mercantil resulta ciertamente dudosa. Una buena demostración de este hecho -y de cómo la dependencia efectivamente juega un rol en esta materia- es una comparación de las monedas de las regiones arriba señaladas; sobre todo cuando la moneda es comprendida como un sistema simbólico que representa a la comunidad política. Mientras en Estados Unidos el dólar sigue encarnando el poder internacional de la nación, la Unión Europea vigoriza mediante la creación de una moneda común -el Euro- los motivos para que los sujetos se sientan más hijos de Europa que de sus propios países. Ambos casos demuestran como hoy en día el sistema monetario puede seguir representando un sentimiento de identidad común, en tanto designa una diferencia hacia otros. ¿Y qué sucede en América Latina? "[...] La pérdida de control de las economías de cada país se manifiesta en la desaparición de la moneda propia (Ecuador, El Salvador), en sus devaluaciones frecuentes (Brasil, México, Perú, Venezuela) o en la fijación maníaca al dólar (Argentina). Las monedas llevan emblemas nacionales, pero ya representan poco de la capacidad de las naciones para gestionar soberanamente su presente. No son referencias de realidad, aunque en los intentos de revalorizar su moneda y devolverla del delirio hiperinflacionario a una relación verosímil con el país, Brasil la haya redesignado precisamente como real",42.

\footnotetext{
${ }^{42}$ Néstor García Canclini, op. cit. 2001, p. 25.
} 
Como el mismo García Canclini señala ${ }^{43}$, pareciera ser que América Latina se encuentra frente a dos opciones: globalizarse o defender su identidad. En esta región -a diferencia de lo que sucede en Europa- por el momento no existe la opción de realizar una integración regional que pueda representar un camino de globalización con identidad. Pues es muy poco probable que se generen órdenes eficaces de cooperación regional, porque ante economías frágiles, sociedades civiles débiles e inestabilidad de los sistemas políticos, simplemente no están presentes los elementos básicos para la constitución de formas de regional governance. En definitiva, puede plantearse que identidad y modernización son dos caras de una misma moneda. Pero en la actualidad, aumenta la tensión entre ambos componentes; sobre todo para los países latinoamericanos. Para ellos es sumamente difícil encontrar un camino de modernización que simultáneamente aporte elementos para la construcción de una identidad nacional y/o regional. Dado que estos países mantienen un lugar periférico en el mundo, se encuentran ellos en una posición de partida desigual e inferior al momento de establecer procesos de globalización. Esto implica que la hibridación opera cada vez más de forma heterónoma que endógena, es decir, hay una mayor asimilación de lo extranjero que la capacidad de rearticular lo nacional. Pareciera que los países latinoamericanos no tuviesen tiempo para pensar como debería continuar su inserción a una realidad globalizada. Quizás estas reflexiones son un privilegio de los países desarrollados. Mientras Europa puede imaginar un potencial futuro mediante su integración y nada indica que Estados Unidos vaya a perder su posición hegemónica mundial, escasean en Latinoamérica elementos que permitan teorizar desde la sociología una mirada positiva sobre la globalización. Dicho de forma metafórica: los países de América Latina compiten en una carrera, pero han comenzado desde muy atrás. Por esto deben ellos correr muy rápido. De tal manera, recién durante la carrera comienzan a pensar por qué están haciendo esto y cuáles son las consecuencias.

${ }^{43}$ Néstor García Canclini, op. cit. 2000, p. 21. 